\title{
Social Support and Academic Burnout Among University Students: A Moderated Mediation Model
}

\author{
Yuqiao $\mathrm{Ye}^{1,2, *}$ \\ Xiuyu Huang ${ }^{2,3, *}$ \\ Yang Liu ${ }^{4, *}$
}

'Shaanxi Key Laboratory of Behavior and Cognitive Neuroscience, School of Psychology, Shaanxi Normal University, Xi'an, People's Republic of China; ${ }^{2}$ School of Psychology, South China Normal University, Guangzhou, People's Republic of China; ${ }^{3}$ Center for Smart Health, School of Nursing, The Hong Kong Polytechnic University, Kowloon City, Hong Kong; ${ }^{4}$ Department of Physical Education, Shaanxi Normal University, Xi'an, People's Republic of China

*These authors contributed equally to this work
This article was published in the following Dove Press journal:

Psychology Research and Behavior Management

\begin{abstract}
Purpose: An increasing number of studies have been carried out to investigate the relationship between social support and study motivation among university students, but underlying mechanisms behind this pathway have not been fully verified. In the present study, we aimed to test the effect of social support on academic burnout (decrease in study motivation); examine the mediating effect of life satisfaction on the association between social support and academic burnout; and explore whether this mediating effect varied across (moderated mediation) students of different socioeconomic status (SES).
\end{abstract}

Materials and Methods: Data for 503 students were collected in a Chinese university through a composited survey regarding social support, life satisfaction, SES, and academic burnout. Data analysis and the investigation of combined effects in the model were carried out via conditional process modeling.

Results: Results indicated that social support was negatively associated with academic burnout. In addition, life satisfaction had a partial mediation effect on the relationship between social support and academic burnout, and SES moderated this mediation effect. Specifically, the mediation effect was found to be more significant among students in the high SES group than those in the lower one.

Conclusion: This study is novel in that it establishes empirically how academic burnout is associated with a typical society analytical variable (ie, social support) among students in tertiary education. It also investigates an alternative scenario to explain the underlying mechanism of social support on academic burnout against the most popular explaining model. Implications of the study for effective elimination of the decrease in study motivation across students with different SES are discussed.

Keywords: social support, life satisfaction, socioeconomic status, academic burnout, mediation effect, moderated mediation effect

\section{Introduction}

Academic burnout was originally derived from the term "job burnout" in the workplace. ${ }^{1}$ Although students are not workers as such, from the perspective of psychology, bachelor studies comprise structured events, including course attendance, assignments and examinations, which can be regarded as "work".,2,3 Students in a burnout state often feel exhausted and adopt a cynical, withdrawn motivation towards their studies. ${ }^{4}$ The syndrome of academic burnout is analogous to that of employees, which is associated with higher absence, higher percentage of dropout, and a decrease in academic performance. ${ }^{3}$ It is apparent that the academic burnout does harm a student's career. Numerous research groups have shown a high prevalence of burnout in universities. ${ }^{1,5-8}$ They provided
Correspondence: Yang Liu

Department of Physical Education,

Shaanxi Normal University, Xi'an, People's

Republic of China

Email liuyang0330@snnu.edu.cn

Yuqiao Ye

Shaanxi Key Laboratory of Behavior and

Cognitive Neuroscience, School of

Psychology, Shaanxi Normal University,

Xi'an, People's Republic of China

Email yuqiaoye@outlook.com 
consistent evidence indicating that social support (environmental resources) is a crucial factor contributing to a decrease in the level of academic burnout. Social support is a feeling that one is being cared for, able to obtain assistance from others, and more importantly, is a member of a supportive network. ${ }^{9}$ Students with various social supports can more easily seek help to address the burnout issue. The above-mentioned studies ${ }^{1,5-8}$ mainly focused on the direct relationship between social support and academic burnout. They usually only considered social support as a significant protective barrier directly against academic burnout without considering the latent mechanism (eg, indirect effects) behind the association. ${ }^{1,5,6}$

In response to this research gap, the purpose of this study was to investigate the possible mediating effect of life satisfaction and moderated effect of SES on the association between social support and academic burnout using a moderated mediation model. Specifically, we tested if social support was indirectly related to academic burnout through life satisfaction and if this mediation effect was moderated by SES (wealthy vs poor). A deep comprehension of these effects not only offers students guidance with which to manage study motivation themselves, but also enables teachers and parents to deliver targeted interventions to students with different socioeconomic backgrounds.

\section{Life Satisfaction as a Mediator}

Although much research has been focused on the role of social support on study motivation (eg, academic burnout), little is known other than the direct relationship. Previous studies have tested various possible indirect links between social support and burnout, such as co-rumination, organizational identification, work-family conflict and degree of religiousness. ${ }^{10-14}$ However, most proposed pathways were targeted to samples in the workplace, while students were less catered for. Life satisfaction, as a psychological emotion, is critical to college student development and adaptation to university life. ${ }^{15}$ It has been proved to be significantly associated with students' perceptions of the quality of a university, the ability to self-learn, the sense of belonging to the university community, and study performance. ${ }^{16-19} \mathrm{We}$ believe that this psychological strength could act as a crucial transformed component of the effect of the received social support on academic burnout.

In university life, sufficient support from multiple sources through family members, teachers, and peers leads to various productive effects on life assessment. ${ }^{20}$ For example, teachers and schoolmates can provide useful suggestions on academic tasks so that students may relieve their study burdens and adopt an optimistic attitude. Also, according to the Conservation of Resources Model (COR), ${ }^{21}$ social support is a conditional resource. It can offer mental assistance in handling anxiety, strain, or depression and subsequently helps amend students' self-respect, self-perception, and selfefficacy. ${ }^{22}$ In general, adequate social support provides both external and internal positive effects on a wide range of aspects of life satisfaction among students.

Life satisfaction not only simply inherits the social support effect, but also has an association with a student's study status. As shown in previous studies, high life satisfaction is regarded as the reflection of positive emotion towards different dimensions of life. ${ }^{23,24}$ The Broaden-and-Build theory of positive emotions (BBT) suggests that an individual with positive emotions was more likely to be open-minded and self-directed during their academic life. ${ }^{25}$ Moreover, students with high life satisfaction also have fewer improper behaviors and lower study dropout rates according to cross-sectional experiments. ${ }^{26,27}$ These interesting phenomena all raise the possibility that a high level of life satisfaction could not only increase the positive effects on study but reverse the negative ones. Thus, life satisfaction was regarded as a determining factor in academic burnout.

The buffering-effect model theory proposed by Cohen and Wills ${ }^{28}$ is one of the most popular models to explain how social support influences strain. It suggests that social support would activate personal objectives and indirectly protect an individual from the negative effects of strain via these activated objectives (eg, life satisfaction). Academic burnout, as a common consequence of high study strain, might have a similar pattern; that is, a personal objective may exist in the relationship between social support and academic burnout. To our knowledge, limited research effort has been devoted to examining this indirect path among university students. By considering these points, we employed Cohen and Wills' model and hypothesized that life satisfaction mediated the relationship between social support and academic burnout.

\section{Socioeconomic Status as a Mediator}

Although a high level of social support might strengthen life satisfaction and undermine academic burnout, the effects of social support may not be consistent across students with different characteristics. A better understanding of the difference in the mediating process in 
divergent groups has critical implications on effective intervention design for academic burnout issues. A previous study showed that the educational attainment of a citizen in a wealthy country was dependent on his/her life satisfaction. ${ }^{29}$ We assumed this conditional dependence on SES of life satisfaction could be transformed from a country level into a personal perspective. Moreover, the effects of life satisfaction (internal subjective well-being) on perceived status varied among people under different situations, ${ }^{30,31}$ while the effects of social support (external objective) tended to be static. ${ }^{32}$ Thus, the present study focused on examining if the second stage of the mediation process (eg, life satisfaction-academic burnout association) would be moderated by SES among university students.

According to the Need Hierarchy Theory, ${ }^{33}$ individuals' purchases change from material necessities to emotional expression with an increase in SES. As a distinct type of negative emotion, a lack of self-efficacy in study, such as academic burnout, is likely to primarily present among students of high SES when they are dissatisfied with their current life than in those of low SES who struggle in their basic living. Furthermore, studies also suggest that students with a high SES have more and flexible options in their career and are able to commit to interesting fields where the extent of satisfaction is the priority of study motivation. ${ }^{34}$ However, students in lowincome families were inculcated with the idea of "It is the knowledge that upgrades one's life' being the major motivation of their study. Thus, their interests and satisfaction may not have such a strong effect on their study motivation compared to high-SES students. Based on the theoretical evidence, life satisfaction effects on academic burnout were expected be more potent among high SES students than the low ones.

\section{The Present Study}

Our study aimed to offer a differentiated picture of the relationship between social support and academic burnout among university students by testing a simple mediation and a moderated mediation. ${ }^{35}$ According to the above literature review, we hypothesized that (i) the association between social support and academic burnout would be mediated by life satisfaction, and (ii) that the second stage of the mediated path would be moderated by SES (Figure 1). Specifically, we hypothesized that the negative indirect effect of social support on academic burnout, through life

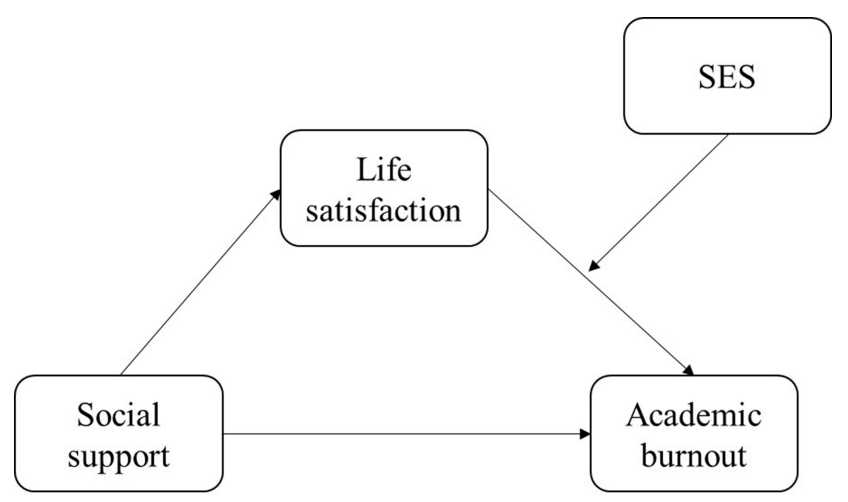

Figure I Moderated mediation model predicting academic burnout. Abbreviation: SES, socioeconomic status.

satisfaction, would be stronger in students lived in high SES.

\section{Materials and Methods Participants}

The data used in the study were collected from students in a university located in China during the middle of the semester (the end of April). We planned to collect data from 600 samples by referring the sample size $(n=320)$ of an analogous study ${ }^{36}$ and the subject selection approach described below. As most statisticians made a consensus that the minimum sample size to get any kind of meaningful result is 100 (better not exceed 1000), ${ }^{37}$ we assumed that the collected sample size of our study should be adequate. Due to the absence of 13 students who withdrew from the study, a total of 587 surveys were eventually collected, of which 502 were valid, without missingvalue items. All the subjects voluntarily participated in the study. One hundred and eleven $(22.11 \%)$ of the subjects were males, and $391(77.89 \%)$ were females. The gender imbalance of the collected data was due to two reasons: (1) the proportion of males to females in the university is approximately $3: 7$; (2) the missing-value items were slightly more common in the surveys (removed from the analysis) filled by males, which further decreased the sex ratio in the data distribution. We finally selected two groups of subjects based on their socioeconomic status measured by three questions (see Section 2.2.4), ie, the top and bottom $27 \%^{38}$ out of 503 participants. These two groups were respectively labeled as "high SES students" and "low SES students", with 136 students in each group. Thus, only 272 subjects were included in the data analysis. Their mean age was 21.87 years $(\mathrm{SD}=1.19)$. 


\section{Measure}

All items for measures were administrated in Chinese. Only Chinese and English scales were used in the study. The English scales were translated into Chinese by academic professors in psychology, and the translated versions have been verified and published in peer-reviewed journals in China. All scale scores were computed by calculating the mean of the items after reverse-coding the necessary ones. For all final scores, higher values indicate higher levels of measures.

\section{Social Support}

Social support was measured with the 10-item Social Support Rating Scale (SSRS) developed by Xiao. ${ }^{39}$ The SSRS is the most commonly used and reliable tool for social support assessment in China with successfully application in many previous studies. ${ }^{40-42}$ It measured three dimensions of social support including subjective support (four items), objective support (three items) and support-seeking behavior (three items). An example of the items was: "How many close relationships can back you up when you are facing difficulties?". For each dimension, a higher scale value indicated a higher level of received support. The overall Cronbach's alpha was 0.76 .

\section{Life Satisfaction}

Students' life satisfaction was assessed using the Satisfaction with Life Scale (SLS) designed by Diener, Emmons, Larsen, Griffin. ${ }^{43}$ It measured global cognitive judgments towards an individual's life satisfaction, with five 7-point Likert items (where 1 = strongly disagree and $7=$ strongly agree). The items reflected the overall satisfaction of the university students with their quality of life. The internal reliabilities of SWLS were 0.78 to 0.82 , as published in different reports in the Chinese context. ${ }^{44-46}$ Examples of the items included "I am satisfied with my life" and "The conditions of my life are excellent". The Cronbach's alpha for SLS was 0.78 .

\section{Academic Burnout}

The Academic Burnout Scale (ABS) invented by Rong, Lixian and Lanhua was used to measure academic burnout among university students. ${ }^{47}$ It is considered a reliable assessment tool for academic burnout in the Chinese context. ${ }^{48}$ The scale consisted of three separate components of academic burnout: study depression ( 8 items), misconduct (6 items) and a low sense of achievement (6 items), for a total of 20 items. For example, the items include "Unit assessment makes me feel disgusted", "I fall asleep during lectures" and "I feel the obtained knowledge from courses are useless". Items were rated on a 5-point Likert scale ranging from 1 (completely inconsistent) to 5 (fully consistent). The Cronbach's alpha of this measure was 0.87 .

\section{Socioeconomic Status}

We assessed SES by asking participants to indicate their agreement to three statements: (a) "I have enough money to buy things I want"; (b) "I don"t need to worry too much about paying my bills'; and (c) "I don"t think I will have to worry about money too much in the future', on a 7-point Likert scale (where $1=$ strongly disagree and $7=$ strongly agree). These three statements were developed by Griskevicius et al to evaluate SES in their studies. ${ }^{49,50}$ They were used to measure the extent to which people feel resource-deprived in the present and foresee the future regarding their socioeconomic status. Although there are several measures for the SES evaluation, including income, education and occupation, undergraduate students share a similar identity in terms of these measures. Under this circumstance, perceived resource availability (plentifulness vs scarcity) is an alternative significant indicator of SES. ${ }^{49,50}$ The trustworthiness of these three statements on the assessment of SES is evident by the high internal reliability in both Griskevicius et al.'s two studies, which were cited by other researchers over 1100 times. ${ }^{49,50}$ In their studies, the high SES and low SES groups were welldiscriminated, with means above and below \pm 1 standard deviations (SDs) from the mean of SES. In the present study, as an additional check, the group division strategy designed by Kelley (for a slightly greater number of participants included) was applied to identify the two groups of students with distinct SES. ${ }^{38}$ According to the mean score of the three Griskevicius et al items, the top 27\% (136 students) of the 503 subjects were defined as the "high SES" group, and the bottom 27\% (136 students) were defined as the "low SES" group. The reported internal reliability of our study was 0.87 .

\section{Control Variables}

Researchers have shown that family location has an association with SES. ${ }^{51}$ To address this bias, family location was included as a control variable in the study. It was measured using the item: "Were your family in a rural (rural $=0$ ) or urban (urban $=1$ ) area?". We also controlled gender $($ male $=0$, female $=1)$ in the analysis. 


\section{Procedure}

The study protocol was approved by the Ethics Committee of the South China Normal University prior to the commencement and followed the Declaration of Helsinki for research involving human subjects. The data were collected from a simple random sample of undergraduate students at the university in person within one day. We first explained the study as well as the confidentiality measures and reimbursement for participation (10 Chinese Yuan paid to each participant after the data collection). After the informed consent (upon disclosure of the experiment information and voluntary nature of participation) was obtained from the students, they were requested to fill in a short survey that contained multiple items including gender, age and grade. To be included in the study, participants needed to be an official current student and between 18 and 25 years of age. $\mathrm{He} / \mathrm{she}$ was finally asked to complete a composited survey containing all the measures analyzed in the study after the eligibility confirmation. Both two mentioned surveys were completed with pen and paper.

\section{Statistical Analysis}

We carried out all statistical analyses of the present study using IBM SPSS version 21 software. The descriptive statistics of our samples and the inter-factor correlations for the selected variables were employed before the hypothesis testing, which showed the statistical characteristics of the participants. A conditional process analysis with a bootstrapped approach (PROCESS) $^{35}$ was then applied to test the mediating (ie hypothesis (i)) and moderated mediating (ie hypothesis (ii)) effects.

\section{Result}

\section{Bivariate Analyses (Descriptive Statistics and Correlation)}

Table 1 shows the mean (M) (for ordinal or continuous variables) or frequency (F) (for categorical variables), standard deviation (SD), and intercorrelation for all measures in our study. Social support was found to be positively associated with life satisfaction $(r=0.28, p<0.001)$ but negatively correlated with academic burnout $(\mathrm{r}=-0.27, \mathrm{p}<$ 0.001 ). Life satisfaction was found to be significantly correlated with academic burnout $(\mathrm{r}=-0.35, \mathrm{p}<0.001)$. These above results indicate that the independent variable, dependent variables, and mediated variable in our proposed model were all significantly correlated with each other.

\section{Mediation Analysis}

Next, we tested the mediation effect of life satisfaction on the association between social support and academic burnout. According to Preacher and Hayes, ${ }^{52}$ the mediation effect would only be tested when the independent and dependent variables were significantly related. This prerequisite was satisfied, as shown by the bivariate analysis in the previous subsection.

We used the 'Model 4' in the PROCESS macro developed by Hayes in the IBM SPSS software to test our mediation hypothesis. ${ }^{35}$ The macro generated bootstrapped (5000 bootstraps were used in our study) confidence intervals which did not contain zero, which indicated a significant mediation effect. ${ }^{52}$ All continuous variables were normalized through the z-score approach before the test. SES, family location, and gender were dummy coded

Table I Means (M)/Frequencies (F), Standard Deviations (SD), and Intercorrelations of Study Variables

\begin{tabular}{|c|c|c|c|c|c|c|c|}
\hline Variable & M/F & SD & $\mathbf{I}$ & 2 & 3 & 4 & 5 \\
\hline I. Social support & 38.47 & 5.10 & I & & & & \\
\hline 2. Life satisfaction & 18.96 & 5.27 & $0.28^{* * *}$ & I & & & \\
\hline 3. Academic burnout & 55.16 & 10.63 & $-0.27 * * *$ & $-0.35 * * *$ & l & & \\
\hline 4. SES & $\begin{array}{l}\text { Wealth:I36 } \\
\text { Poor: I36 }\end{array}$ & I & -0.01 & 0.04 & -0.01 & l & \\
\hline 5. Family location & $\begin{array}{l}\text { Rural: } 180 \\
\text { Urban: } 92\end{array}$ & I & -0.04 & -0.05 & 0.06 & 0.02 & l \\
\hline 6. Gender & $\begin{array}{l}\text { Male: } 34 \\
\text { Female:238 }\end{array}$ & I & -0.13 & 0.03 & -0.05 & $0.13 *$ & 0.04 \\
\hline
\end{tabular}

Notes: ${ }^{*} p<0.05 ; * * * p<0.001$ 
A Conceptual diagram

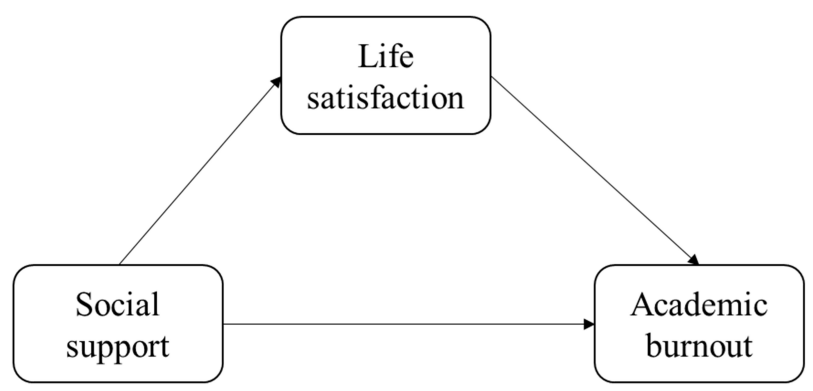

B Statistical diagram

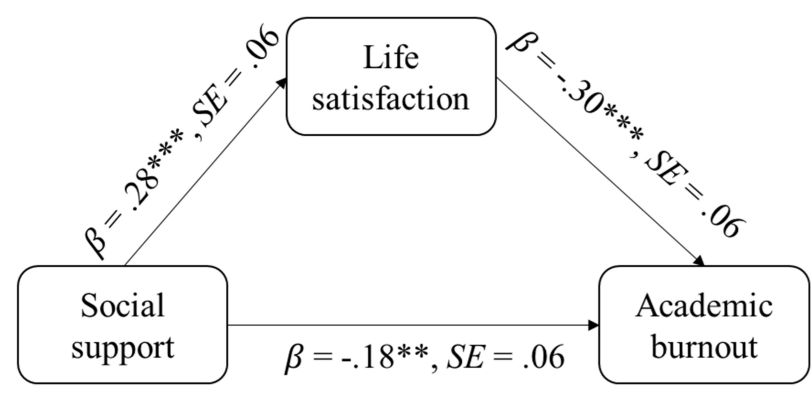

Figure 2 Mediation model of social support to life satisfaction to academic burnout: (A) Conceptual diagram; (B) Statistical diagram. Notes: $* * p<0.01$. ${ }^{* * *} p<0.001$.

to 0 and 1 . Control variables including family location and gender were assigned as covariates in the test.

The mediation model (Figure 2) with both predictors and covariates explained $16 \%$ of the variance of academic burnout $\left(R^{2}=0.16, \mathrm{p}<0.001\right)$. The result from biascorrected bootstrapping indicated a significant mediation effect $(\beta=-0.08, \mathrm{SE}=0.03$, CI $[-0.14,0.04])$. Thus, life satisfaction was found to mediate the relationship between social support and academic burnout.

\section{Moderated Mediation Analysis}

We used 'Model 14' in the PROCESS macro to examine the moderated mediation effect, ie, part (ii) of our hypothesis. The macro also generated a 5000-bootstrap

A Conceptual diagram

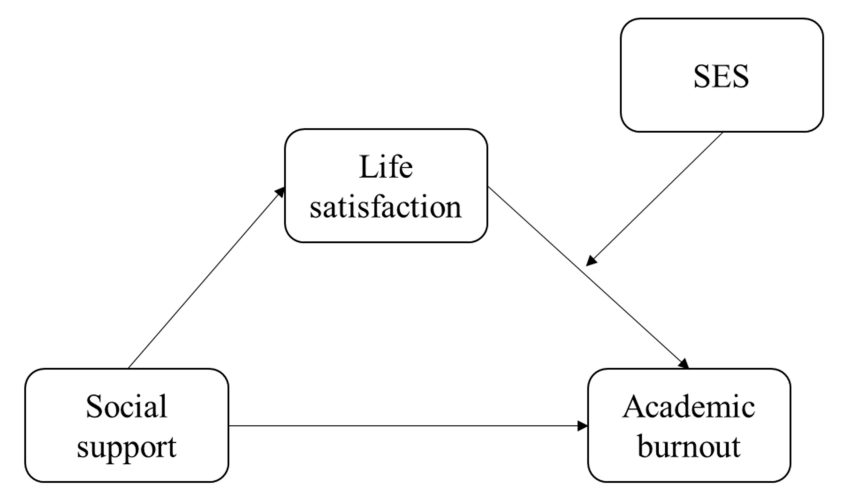

confidence interval (without zero) for the significance test. An illustration of the model is presented in Figure 3.

Results showed that approximately $18 \%$ of the variance of academic burnout was explained by social support, life satisfaction, SES, the interaction between life satisfaction and SES, and covariates $\left(R^{2}=0.18, \mathrm{p}<\right.$ 0.001 ). Indirect effects of social support on academic burnout were significant for both the high SES group ( $\beta=$ $-0.13, \mathrm{SE}=0.04, \mathrm{CI}=-0.22$ to -0.05$)$ and the low SES group $(\beta=-0.05, \mathrm{SE}=0.02, \mathrm{CI}=-0.10$ to -0.01$)$. However, the negative indirect effect at high SES was significantly stronger than that at low SES, as no zero value was returned in the bootstrapping index of moderated mediation $(\beta=-0.08, \mathrm{SE}=0.04, \mathrm{CI}[-0.17,-0.01])$.

B Statistical diagram

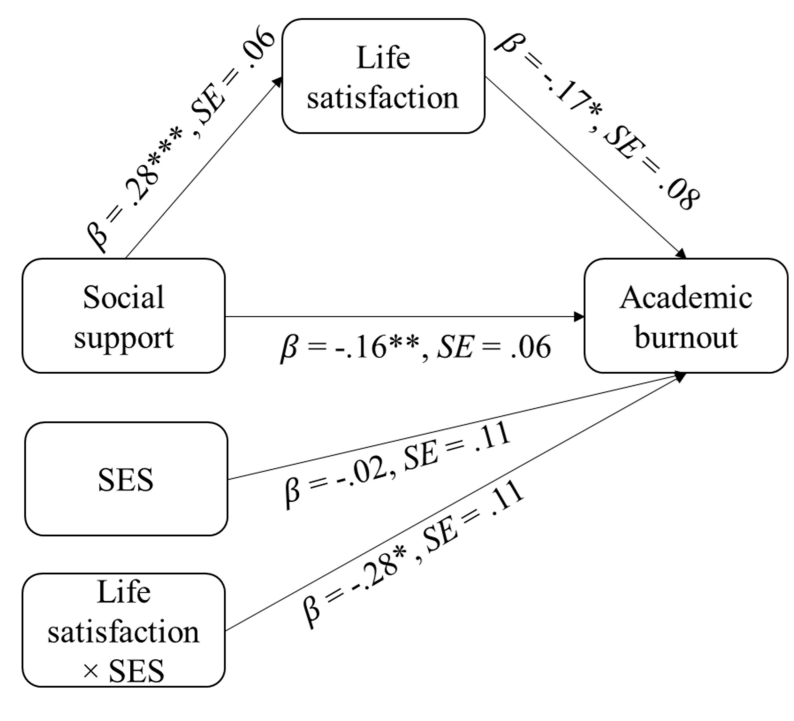

Figure 3 Socioeconomic status (SES) moderated the mediation model of social support to life satisfaction to academic burnout: (A) Conceptual diagram; (B) Statistical diagram.

Notes: ${ }^{*} p<0.05$. $* * p<0.01$. *** $p<0.001$.

Abbreviation: SES, socioeconomic status. 
This result supported the proposed moderated mediation effect.

\section{Discussion}

The aim of the present study was to investigate the mediation effect of life satisfaction on the social support-academic burnout association and the function of SES on the mediation effect. The results suggest a significant social support-academic burnout association and a significant mediated effect of life satisfaction upon this association. Additionally, this indirect pathway varied across students with different SES. Specifically, the indirect link was more potent among high-SES students. Our findings offer a novel and crucial understanding of how social support is associated with academic burnout among university students and the difference in the mediating process between high and low SES groups. We believe the current study can expand the literature by offering empirical evidence for the mechanism by which social support affects academic burnout.

Consistent with previous studies, ${ }^{1,5,6}$ we found social support dissimilarity in academic burnout among university students. As expected, the results indicated that life satisfaction is a key underlying psychological assessment/ emotion, contributing to the explanation of why an increase in social support is associated with less academic burnout. Students receiving more support were more likely to be satisfied with their life, and in turn may have less academic burnout. In line with the buffer-effect model proposed by Cohen and Wills, ${ }^{28}$ our findings suggest that optimism in life assessment (personal objective) may be activated by the increment of social support, and this activated optimism of life may, in return, act as a shield to prevent an individual from falling into academic burnout. ${ }^{53}$ On the other hand, for those encountering stressful or exhaustive conditions, sufficient social support is likely to create a positive perception of life assessment, regardless of the physical resource reality, which will help them pull themselves out of the academic burnout state. Moreover, as shown in Section (b) of Figure 2, the direct path of social support-academic burnout remained significant after the involvement of the significant mediating effect of life satisfaction, which means the direct and indirect path from social support both contributed to the variance of academic burnout. This interesting finding offers a different scenario against the buffer-effect model. ${ }^{28}$ Social support may not only convey its effects indirectly, via other factors associated with academic burnout, but also deliver its effect directly on academic burnout. $^{28,54}$ This substantiates the theoretical framework that social support affects academic burnout both internally and externally. As stated above, social support is likely to prevent or eliminate academic burnout by activating an individual's internal perception (eg, life satisfaction). Also, it may operate as external assistance (eg, parent care, peer advice, and supervisor feedback) for direct academic burnout alleviation.

Another interesting finding was that the indirect effect of social support on academic burnout via life satisfaction increased as the SES improved. The reason behind the expected changes across SES may be the different roles of life attitude on academic burnout in students of different SES. As it is expected that the basic external demands of students of high SES, including physiological and safety needs in their life, can be readily fulfilled, the extent of their life satisfaction is mainly determined by other higher levels of internal requirements, such as social needs, esteem, and self-actualization. ${ }^{33}$ This internally oriented life satisfaction may be more likely to have a greater effect on academic burnout, which is also an internal status of exhaustion. Conversely, as stated by $\mathrm{COR}^{33}$ the extent of life satisfaction among students who live in adversity is largely based on low-level external material demands, so their life assessment may not be reflected in the internal academic burnout as much as those living in a wealthy family. These findings provide initial support for the unique role played by perceived resource availability as a reliable indicator of SES in the observed differential in academic burnout between the two SES groups. As mentioned in the Introduction, several research groups reached a consensus on a positive relationship between social support and life satisfaction across multiple groups of people. $^{30,31}$ Thus, our hypothesis on moderated effect were only tested at the second stage (life satisfactionacademic burnout) of the indirect effect instead of the first stage (social support-life satisfaction). Our result may explain why the indirect link has various effects on academic burnout among students with different SES: for the two groups of students, there are different roles of life satisfaction in academic burnout, rather than different roles of social support in life satisfaction.

Many students have difficulties in adapting to university life, ${ }^{55}$ where a large number of assigned study tasks may increase their burnout during semesters. Our finding may offer important implications for addressing the increased prevalence of burnout. First, our study provides 
empirical evidence of the social support-life satisfactionacademic burnout partial mediation model. This suggests that academic intervention could be targeted to various supports to increase life satisfaction. For example, parents could provide more instrumental and emotional care. Teachers can deliver views on the importance of social support from peers, family, and lecturers to the students and offer guidance on how to obtain that support from the university community. Universities can establish diverse and accessible facilities for both academic and mental assistance. Second, our finding shows that SES acts as a significant moderator of social support on academic burnout. This suggest that interventions for academic burnout could be designed to cater for students with different SES levels. Programs to address academic burnout among high-SES students could be mainly concentrated on emotional factors, including study interests and a sense of achievement. Alternatively, programs for students living in adverse conditions could emphasize financial needs and elimination of the negative effect of social comparison due to prejudice and bias.

Consistent with other studies, ${ }^{46,56}$ it is important to be aware of the limitations in the present study before practical use of the findings. First, due to the cross-sectional design of the current study, the temporal sequence (causality) of the independent variables, mediator, moderator, and dependent variables cannot be verified. ${ }^{57}$ A longitudinal approach could be carried out in further study to explore more causal assessments and offer a more fruitful picture of how social support impacts academic burnout among university students over time. Second, it was also noted that our subjects were drawn from a single source (undergraduate students) within only one cultural background (China), which limits the generalizability of our findings. Masters and doctoral (graduate) students are more concentrated on innovative academic exploration, which is different from the study of bachelor degree students, and students of different backgrounds naturally have various characteristics. Thus, students from other sources (eg, masters and $\mathrm{PhD}$ ) and other backgrounds (eg, from other countries) should be also further tested in our model to expand the generalizability of our findings.

\section{Conclusion}

Supports from society are crucial for university students and affect their motivation towards study. ${ }^{58}$ A better comprehension of the social support-academic burnout relationship and the mechanism of this direct association remains a priority for the design of intervention programs for academic burnout. ${ }^{59}$ The findings of the present study highlight that life satisfaction plays a significant mediating role in the association between social support and academic burnout. SES was also found to have a significant moderating effect on this indirect path. It is hoped that the initial findings of the study will encourage more studies targeting an investigation of student academic burnout (study motivation), thereby yielding a clear and comprehensive understanding of the underlying mechanisms between social support and academic burnout for different student characteristics and backgrounds.

\section{Funding}

This research was supported by the Fundamental Research Funds for the Central Universities (Program No. GK202007035).

\section{Disclosure}

The authors report no conflicts of interest in this work.

\section{References}

1. Kim B, Jee S, Lee J, An S, Lee SM. Relationships between social support and student burnout: a meta-analytic approach. Stress Health. 2018;34(1):127-134. doi:10.1002/smi.2771

2. Balogun JA, Hoeberlein-Miller TM, Schneider E, Katz JS. Academic performance is not a viable determinant of physical therapy students' burnout. Percept Mot Skills. 1996;83(1):21-22. doi:10.2466/pms.19 96.83.1.21

3. Jacobs SR, Dodd D. Student burnout as a function of personality, social support, and workload. J Coll Stud Dev. 2003;44(3):291-303. doi:10.1353/csd.2003.0028

4. Schaufeli WB, Salanova M, González-Romá V, Bakker AB. The measurement of engagement and burnout: a two sample confirmatory factor analytic approach. J Happiness Stud. 2002;3(1):71-92. doi:10. 1023/A:1015630930326

5. Karimi Y, Bashirpur M, Khabbaz M, Hedayati AA. Comparison between perfectionism and social support dimensions and academic burnout in students. Procedia Social Behav Sci. 2014;159:57-63. doi:10.1016/j.sbspro.2014.12.328

6. Popa-Velea O, Diaconescu L, Mihailescu A, Jidveian Popescu M, Macarie G. Burnout and its relationships with alexithymia, stress, and social support among romanian medical students: a cross-sectional study. Int J Environ Res Public Health. 2017;14 (6):560. doi:10.3390/ijerph14060560

7. Lian P, Sun Y, Ji Z, Li H, Peng J. Moving away from exhaustion: how core self-evaluations influence academic burnout. PLoS One. 2014;9 (1):e87152. doi:10.1371/journal.pone.0087152

8. Chang E, Lee A, Byeon E, Seong H, Lee SM. The mediating effect of motivational types in the relationship between perfectionism and academic burnout. Pers Individ Dif. 2016;89:202-210. doi:10.1016/j. paid.2015.10.010

9. Guruge S, Thomson MS, George U, Chaze F. Social support, social conflict, and immigrant women's mental health in a Canadian context: a scoping review. J Psychiatr Ment Health Nurs. 2015;22(9):655-667. doi: $10.1111 / \mathrm{jpm} .12216$ 
10. Boren JP. The relationships between co-rumination, social support, stress, and burnout among working adults. Manag Commun $Q$. 2013;28(1):3-25. doi:10.1177/0893318913509283

11. Avanzi L, Fraccaroli F, Castelli L, et al. How to mobilize social support against workload and burnout: the role of organizational identification. Teach Teach Educ. 2018;69:154-167. doi:10.1016/j. tate.2017.10.001

12. Blanch A, Aluja A. Social support (family and supervisor), workfamily conflict, and burnout: sex differences. Human Relations. 2012;65(7):811-833. doi:10.1177/0018726712440471

13. Gonzalez MA. Study of the Relationship of Stress, Burnout, Hardiness, and Social Support in Urban, Secondary School Teachers [Unpublished Doctoral Dissertation]. Philadelphia, PA: Temple University; 1997.

14. Yoon DP, Lee E-KO. The impact of religiousness, spirituality, and social support on psychological well-being among older adults in rural areas. J Gerontol Soc Work. 2006;48(3-4):281-298. doi:10. 1300/j083v48n03_01

15. Ojeda L, Castillo LG, Rosales Meza R, Piña-Watson B. Mexican Americans in higher education: cultural adaptation and marginalization as predictors of college persistence intentions and life satisfaction. J Hispanic High Educ. 2014;13(1):3-14. doi:10.1177/ 1538192713498899

16. Audin K, Davy J, Barkham M. University Quality of Life and Learning (UNIQoLL): an approach to student well-being, satisfaction and institutional change. J Further High Educ. 2003;27(4):365-382. doi:10.1080/0309877032000128073

17. Ma X, Guo X, He Y, Bai F. Study on the correlation between self-learning ability and life satisfaction of undergraduate practice nurses. Paper presented at: 5th Annual International Conference on Management, Economics and Social Development (ICMESD 2019); 2019; Suzhou, Jiangsu, China. doi:10.2991/icmesd-19.2019.80.

18. Civitci A. Perceived stress and life satisfaction in college students: belonging and extracurricular participation as moderators. Procedia Social Behav Sci. 2015;205:271-281. doi:10.1016/j.sbspro.2015.09.077

19. Bjelica DL, Jovanović UD. It's up to you: the influence of sports participation, academic performances and demo-behavioral characteristics on university students' life satisfaction. Appl Res Qual Life. 2016;11(1):163-179. doi:10.1007/s11482-014-9360-0

20. Garnefski N, Diekstra RFW. Perceived social support from family, school, and peers: relationship with emotional and behavioral problems among adolescents. J Am Acad Child Adolesc Psychiatry. 1996;35(12):1657-1664. doi:10.1097/00004583-199612000-00018

21. Hobfoll SE. Conservation of resources: a new attempt at conceptualizing stress. Am Psychol. 1989;44(3):513-524. doi:10.1037/0003$066 \mathrm{X}$

22. O'Sullivan G. The relationship between hope, eustress, self-efficacy, and life satisfaction among undergraduates. Soc Indic Res. 2010;101 (1):155-172. doi:10.1007/s11205-010-9662-z

23. Lyubomirsky S, King L, Diener E. The benefits of frequent positive affect: does happiness lead to success? Psychol Bull. 2005;131 (6):803-855. doi:10.1037/0033-2909.131.6.803

24. Lyubomirsky S, Sheldon KM, Schkade D. Pursuing happiness: the architecture of sustainable change. Rev Gen Psychol. 2005;9 (2):111-131. doi:10.1037/1089-2680.9.2.111

25. Fredrickson BL. The role of positive emotions in positive psychology - the broaden-and-build theory of positive emotions. Am Psychol. 2001;56(3):218-226. doi:10.1037/0003-066x.56.3.218

26. Hagenauer G, Gläser-Zikuda M, Moschner B. University students' emotions, life-satisfaction and study commitment: a selfdetermination theoretical perspective. $J$ Further High Educ. 2018;42(6):808-826. doi:10.1080/0309877X.2017.1323189

27. Çelik ÇB, Odacı H. The relationship between problematic internet use and interpersonal cognitive distortions and life satisfaction in university students. Child Youth Serv Rev. 2013;35(3):505-508. doi:10.1016/j.childyouth.2013.01.001
28. Cohen S, Wills TA. Stress, social support, and the buffering hypothesis. Psychol Bull. 1985;98(2):310-357. doi:10.1037/00332909.98.2.310

29. Lucas PJ, McIntosh K, Petticrew M, Roberts HM, Shiell A. Financial benefits for child health and well-being in low income or socially disadvantaged families in developed world countries. Cochrane Database Syst Rev. 2008;(2). doi:10.1002/14651858.CD006358.pub2

30. Diener E, Pressman SD, Hunter J, Delgadillo-Chase D. If, why, and when subjective well-being influences health, and future needed research. Appl Psychol Health Well Being. 2017;9(2):133-167. doi:10.1111/aphw.12090

31. Røysamb E, Tambs K, Reichborn-Kjennerud T, Neale MC, Harris JR. Happiness and health: environmental and genetic contributions to the relationship between subjective well-being, perceived health, and somatic illness. J Pers Soc Psychol. 2003;85(6):1136-1146. doi:10. 1037/0022-3514.85.6.1136

32. Fife J, Adegoke A, McCoy J, Brewer T. Religious commitment, social support and life satisfaction among college students. Coll Stud J. 2011;45(2):393.

33. Wahba MA, Bridwell LG. Maslow reconsidered: a review of research on the need hierarchy theory. Organ Behav Hum Perform. 1976;15 (2):212-240. doi:10.1016/0030-5073(76)90038-6

34. Rothstein J, Rouse CE. Constrained after college: student loans and early-career occupational choices. J Public Econ. 2011;95(1-2):149-163. doi:10.1016/j.jpubeco.2010.09.015

35. Preacher KJ, Rucker DD, Hayes AF. Addressing moderated mediation hypotheses: theory, methods, and prescriptions. Multivariate Behav Res. 2007;42(1):185-227. doi:10.1080/00273170701341316

36. Zuheng C, Manyan Z.On the state of psychological resilience and the countermeasures of psychological aid among impoverished undergraduates_a case study of Qinzhou University. J Qinzhou Univ. 2015;30(6):97-100.

37. Conroy R. Sample size: a rough guide; 2015. Available from: http:// www.beaumontethics.ie/docs/application/samplesizecalculation.pdf. Accessed March 10, 2021.

38. Kelley TL. The selection of upper and lower groups for the validation of test items. J Educ Psychol. 1939;30(1):17-24. doi:10.1037/h0057123

39. Xiao S. Theoretical background study and application of social support rate scale. J Clin Psychol Med. 1994;2:98-100.

40. Yu Y, Yang JP, Shiu CS, et al. Psychometric testing of the Chinese version of the medical outcomes study social support survey among people living with HIV/AIDS in China. Appl Nurs Res. 2015;28 (4):328-333. doi:10.1016/j.apnr.2015.03.006

41. Huang Y, Luo D, Chen X, Zhang D, Huang Z, Xiao S. Role of psychosocial status in predicting health-related quality of life at 1-year follow-up among newly diagnosed people living with HIV. PLoS One. 2019;14(10):e0224322. doi:10.1371/journal.pone.0224322

42. Bi F, Luo D, Huang Y, Chen X, Zhang D, Xiao S. The relationship between social support and suicidal ideation among newly diagnosed people living with HIV: the mediating role of HIV-related stress. Psychol Health Med. 2020;1-11. doi:10.1080/13548506.2020.17 61987

43. Diener E, Emmons RA, Larsen RJ, Griffin S. The satisfaction with life scale. J Pers Assess. 1985;49(1):71-75. doi:10.1207/s1532775 2jpa4901_13

44. Kong F, Zhao J, You X. Emotional intelligence and life satisfaction in Chinese university students: the mediating role of self-esteem and social support. Pers Individ Dif. 2012;53(8):1039-1043. doi:10.1016/ j.paid.2012.07.032

45. Wang KT, Yuen M, Slaney RB. Perfectionism, depression. loneliness, and life satisfaction: a study of high school students in Hong Kong. Couns Psychol. 2008;37(2):249-274. doi:10.1177/001100000831 5975.

46. Kong F, You X. Loneliness and self-esteem as mediators between social support and life satisfaction in late adolescence. Soc Indic Res. 2011;110(1):271-279. doi:10.1007/s11205-011-9930-6 
47. Rong L, Lixian Y, Lanhua W. Relationship between professional commitment and learning burnout of undergraduates and scales developing. Acta Psychologica Sinica. 2005;5:632-636.

48. Wang M, Guan H, Li Y, Xing C, Rui B. Academic burnout and professional self-concept of nursing students: a cross-sectional study. Nurse Educ Today. 2019;77:27-31. doi:10.1016/j.nedt.2019. 03.004

49. Griskevicius V, Tybur JM, Delton AW, Robertson TE. The influence of mortality and socioeconomic status on risk and delayed rewards: a life history theory approach. J Pers Soc Psychol. 2011;100 (6):1015-1026. doi:10.1037/a0022403

50. Griskevicius V, Delton AW, Robertson TE, Tybur JM. Environmental contingency in life history strategies: the influence of mortality and socioeconomic status on reproductive timing. J Pers Soc Psychol. 2011;100(2):241-254. doi:10.1037/a0021082

51. Sicular T, Ximing Y, Gustafsson B, Shi L. The urban-rural income gap and inequality in China. Rev Income Wealth. 2007;53(1):93-126. doi:10.1111/j.1475-4991.2007.00219.x

52. Preacher KJ, Hayes AF. Asymptotic and resampling strategies for assessing and comparing indirect effects in multiple mediator models. Behav Res Methods. 2008;40(3):879-891. doi:10.3758/brm.40.3.879

53. Vizoso C, Arias-Gundín O, Rodríguez C. Exploring coping and optimism as predictors of academic burnout and performance among university students. Educ Psychol. 2019;39(6):768-783. doi:10.1080/01443410.2018.1545996
54. Shin H, Lee J, Kim B, Lee SM. Students' perceptions of parental bonding styles and their academic burnout. Asia Pacific Educ Rev. 2012;13(3):509-517. doi:10.1007/s12564-012-9218-9

55. Duque LC. A framework for analysing higher education performance: students' satisfaction, perceived learning outcomes, and dropout intentions. Total Qual Manage Bus Excellence. 2014;25(1-2): 1-21. doi:10.1080/14783363.2013.807677

56. Zhu W, Wang CD, Chong CC. Adult attachment, perceived social support, cultural orientation, and depressive symptoms: a moderated mediation model. J Couns Psychol. 2016;63(6):645-655. doi:10.10 37/cou0000161

57. Rindfleisch A, Malter AJ, Ganesan S, Moorman C. Cross-sectional versus longitudinal survey research: concepts, findings, and guidelines. J Market Res. 2008;45(3):261-279. doi:10.1509/jmkr. 45.3.261

58. Li J, Han X, Wang W, Sun G, Cheng Z. How social support influences university students' academic achievement and emotional exhaustion: the mediating role of self-esteem. Learn Individ Differ. 2018;61:120-126. doi:10.1016/j.lindif.2017.11.016

59. Cheng J, Zhao YY, Wang J, Sun YH. Academic burnout and depression of Chinese medical students in the pre-clinical years: the buffering hypothesis of resilience and social support. Psychol Health Med. 2020;25(9):1094-1105. doi:10.1080/13548506.2019.1709651
Psychology Research and Behavior Management

\section{Publish your work in this journal}

Psychology Research and Behavior Management is an international, peer-reviewed, open access journal focusing on the science of psychology and its application in behavior management to develop improved outcomes in the clinical, educational, sports and business arenas. Specific topics covered in the journal include: Neuroscience, memory and decision making; Behavior modification and management; Clinical

\section{Dovepress}

applications; Business and sports performance management; Social and developmental studies; Animal studies. The manuscript management system is completely online and includes a very quick and fair peer-review system, which is all easy to use. Visit http://www. dovepress.com/testimonials.php to read real quotes from published authors. 